\title{
A AFIRMAÇÃO DA FINITUDE COMO POSSIBILIDADE PARA A RESPONSABILIZAÇÃ̃ DO DESEJO: NOTAS A PARTIR DE HEIDEGGER E LACAN
}

\author{
Renato dos Santos ${ }^{1}$ \\ Pontifícia Universidade Católica do Paraná (PUCPR) \\ Universidade de Coimbra (UC) \\ (iD) https://orcid.org/0000-0002-1402-7162 \\ E-mail: renatodossantos1@hotmail.com \\ Juliana Rodrigues Dalbosco 2 \\ Pontifícia Universidade Católica do Paraná (PUCPR) \\ (iD) https://orcid.org/0000-0002-2690-3860 \\ E-mail: dalbosco.psi@outlook.com
}

\section{RESUMO:}

O propósito deste artigo é o de evidenciar de que forma a afirmação do ser ser-para-a-morte de Heidegger pode ser entendido como condição de possibilidade para a responsabilização do desejo conforme formulado pela psicanálise lacaniana. Primeiro, descreve-se a estrutura do Dasein heideggeriano, bem como seus existenciais. Em seguida, analisa-se o uso e o sentido da noção de desejo em Lacan. Tanto numa existência autêntica, quanto num final de análise, onde o sujeito sabe lidar com suas perdas, diante da angústia, ele assume um papel de protagonista de sua existência e consegue se responsabilizar pelo seu desejo. A análise, nesse sentido, serve como uma ferramenta que possibilita o sujeito lidar com este sofrimento decorrente da falta, deste nada que falou Heidegger. Evidentemente que a análise não objetiva eliminar esta falta ontológica, mas tão somente desconstruir os fantasmas que o sujeito construiu para afastar o que lhe é mais próprio, constitutivo de sua estrutura ontológica, qual seja, sua finitude. Portanto, tanto para Heidegger, por meio da afirmação da angústia frente à morte, quanto para Lacan, onde o sujeito assumiu a tragédia de sua existência - no final de análise -, é a afirmação da finitude que possibilita a responsabilização do desejo, de ser autêntico ou, se preferir, sujeito.

PALAVRAS-CHAVE: Angústia; Desejo; Morte; Heidegger; Lacan.

\section{THE AFFIRMATION OF FINITE AS A POSSIBILITY FOR RESPONSIBILIZATION OF DESIRE: NOTES FROM HEIDEGGER AND LACAN}

\begin{abstract}
:
The purpose of this paper is to demonstrate how Heidegger's claim to being-to-death can be understood as a condition of possibility for the responsibility of desire as formulated by Lacanian psychoanalysis. First, the structure of the Heideggerian Dasein, as well as its existential ones, is described. Next, the use and the sense of the notion of desire in Lacan is analyzed. Both in an authentic existence and at the end of analysis, where the subject knows how to deal with his losses, in the face of anguish, he assumes a role of protagonist of his existence and manages to be responsible for his desire. The analysis, in this sense, serves as a tool that enables the subject to deal with this suffering arising from the lack, of this nothing that Heidegger spoke. Obviously, the analysis does not aim to eliminate this ontological lack, but only to deconstruct the phantasms that the subject has constructed to ward off what is his own, constituting his ontological structure, that is, his finitude. Thus, for Heidegger, through the affirmation of anguish in the face of death, and for Lacan, where the subject has assumed the tragedy of his existence - at the end of analysis - it is the affirmation of finitude that makes it possible to hold the desire, authentic or, if you prefer, subject.
\end{abstract}

KEYWORDS: Anguish; Desire; Death; Heidegger; Lacan.

\footnotetext{
${ }^{1}$ Doutorando em Filosofia pela Pontifícia Universidade Católica do Paraná (PUCPR), Curitiba - PR, Brasil, e pela Universidade de Coimbra (UC), Coimbra, Portugal.

2 Pós-Graduanda em Psicanálise Clínica na Pontifícia Universidade Católica do Paraná (PUCPR), Curitiba - PR, Brasil.
}

SANTOS, Renato dos; DALBOSCO, Juliana Rodrigues. A afirmação da finitude como possibilidade para a responsabilização do desejo: notas a partir de Heidegger e Lacan. Griot : Revista de Filosofia, Amargosa - BA, v.19, n.1, p.215-225, fevereiro, 2019. 


\title{
Introdução
}

\begin{abstract}
Muito tempo depois foi que eu descobri / Que o mundo para mim nunca foi nada bom / Eu vivo sofrendo desde que nasci / A somar desenganos e desilusões / Os amores que arranjo morrem prematuros / É uma luta tremenda para sobreviver / Eu não tenho passado, presente ou futuro / Mesmo assim lhe asseguro que quero viver.

(Nelson Sargento - Muito tempo depois)
\end{abstract}

O trecho da música de Nelson Sargento, que dá abertura ao presente texto, ilustra aquilo que Lacan, em seu Seminário 7 - e que se ocupa em falar acerca da ética da psicanálise -, de "experiência trágica da vida". Trata-se, noutros termos, daquela experiência que todo ser humano enfrenta desde seu nascimento, ou seja, a dor de existir. Mas por que, afinal, sofremos? Conforme veremos ao longo deste artigo, o ser humano é o único ente que possui consciência de sua finitude. $O$ fato de saber que sua existência é finita o faz angustiar-se.

Assim, existem, ao menos, dois modos de encarar tal fato, a saber: afirmar ou esquivar-se da finitude. A respeito disto, Heidegger denominará, respectivamente, de existência autêntica e inautêntica. A primeira diz respeito ao modo pelo qual o Dasein relaciona-se com a angústia diante do seu ser-para-a-morte, tomando o fato do findar de sua existência não como uma determinação ôntica localizável fora de sua estrutura ontológica, mas como o que há de mais próprio em seu modo de ser-aí; a inautenticidade, inversamente, concebe a finitude como um acontecimento exterior da sua estrutura, na medida em que encobre o próprio ser e declina-se na publicidade.

Ora, o que desejamos sustentar, ao longo destas reflexões, é que, se em Heidegger, o Dasein somente consegue ser autêntico na medida em que assume a sua finitude, para Lacan, o sujeito só é capaz de responsabilizar-se por seu desejo quando consegue lidar melhor com a angústia das perdas. Noutras palavras, a afirmação da finitude é a condição de possibilidade pela qual o sujeito conseguirá bancar o seu desejo. Ou, ainda, para fazermos menção às palavras do protagonista da música de Sargento, após constatar a tragédia de sua existência: "Mesmo assim lhe asseguro que quero viver". Tais palavras também se assemelham ao que um sujeito, ao final de uma análise, deverá exprimir, ou seja, mesmo constatando o fato de que a vida não possui nenhum sentido, e que somos finitos por meio de uma castração ontológica, ela ainda vale a pena ser vivida.

\section{A afirmação do ser-para-a-morte como existência autêntica}

Muito se tem falado acerca da noção de ser-para-a-morte, um dos existenciais da estrutura ontológica do Dasein heideggeriano. Todavia, o que se quer aqui é ler este existencial sob à luz de uma perspectiva psicanalítica, mostrando que a finitude, tal como propõe Heidegger, configura-se como algo já dado ao Dasein desde sua facticidade, isto é, seu surgimento no mundo ou, como diz o filósofo (2012, p 691, grifos do autor): "se o Dasein existe, ele já está também dejectado nessa possibilidade", ou seja, "a morte é um modo de ser que o Dasein assume logo que é" (HEIDEGGER, 2012, p. 677, grifo do autor). Por isso o Dasein "existe de nascença e 
morre também de nascença, no sentido de ser-para-a-morte" (HEIDEGGER, 2012, p. 1015).

Próprio da estrutura do Dasein, a morte é algo que não está alhures, que o ente humano virá encontrar algum tempo após seu nascimento. A morte não é uma falta que o sujeito preencherá com o seu findar, por uma espécie de completude. A todo instante o Dasein é afetado por esta possibilidade insuperável e intransferível: “o extremo ainda-não tem o caráter de algo para-que o Dasein se comporta. O final é iminente para o Dasein. A morte não é um subsistente que ainda não se efetivou, não é um último faltante reduzido a um mínimo, mas, ao contrário, é um iminente" (HEIDEGGER, 2012, p. 689, grifos do autor).

Por iminente, Heidegger busca designar o caráter ontológico da morte, isto é, o fato de que ela está precedida na estrutura do Dasein desde o seu lançar no mundo. Somente essa constatação já é suficiente para afastarmos as perspectivas que tomam a morte como um fato ôntico, um acontecimento que irá ocorrer em tal lugar ou data. Por isso, do ponto de vista da ontologia fundamental heideggeriana, a morte deve ser entendida como "uma possibilidade-de-ser que o Dasein tem de assumir cada vez ele mesmo. Com a morte, o Dasein é iminente ele mesmo para ele mesmo em seu poder-ser mais-próprio" (HEIDEGGER, 2012, p. 691). Poder-ser mais próprio porque esta possibilidade é, precisamente, a "impossibilidade-de-ser-aí" (HEIDEGGER, 2012, p. 691), ou se quiser, possibilidade da impossibilidade que se encontra, justamente, dentro do campo de possibilidade do projeto do Dasein.

O que nos interessa destacar, no presente escrito, não é simplesmente a natureza da finitude, a partir da obra de Heidegger. Mas, fundamentalmente, mostrar como este entendimento acerca da morte somente é possível numa dimensão de existência que o filósofo denomina de existência autêntica, ou seja, aquele estado em que o Dasein se vê diante da angústia, a qual revela, precisamente, a morte ${ }^{3}$ : "a angústia diante da morte é a angústia 'diante' do mais-próprio, irremetente e superável poder-ser" (HEIDEGGER, 2012, p. 693). Que não confundamos a angústia diante da morte como angústia de deixar de viver, mas como "abertura de que o Dasein existe como ser projetado para o seu final" (HEIDEGGER, 2012, p. 693, grifo do autor). Antes de adentrarmos mais a fundo no modo de existência autêntica e sua afirmação da finitude, é interessante acompanharmos brevemente outra postura comum diante da morte, isto é, a inautenticidade ou impessoal.

Para Heidegger, o Dasein encontra-se, na maior parte das vezes, preso no impessoal. Nesta dimensão existencial, o Dasein se perde no falatório da publicidade de maneira que o afasta de seu poder-ser mais próprio, isto é, a finitude. Apenas os "outros" morrem, ou "a-gente morre", mas nunca o si mesmo: "este ou aquele que está perto ou está longe 'morre'. Desconhecidos 'morrem' diariamente e a toda hora" (HEIDEGGER, 2012, p. 693). Levado pela publicidade do findar, o Dasein encobre a própria morte pela ideia de que "a-gente também morre uma vez, mas a-gente mesma não é de imediato atingida" (HEIDEGGER, 2012, p. 693).

Na verdade, o que se faz quando se exprime tal afirmação é dizer que o si mesmo não morre, ou, que é ainda pior, o que de fato busca afirmar com isso é a ideia

\footnotetext{
${ }^{3}$ Falei em outro texto sobre o fato de toda angústia ser angústia de morte, a partir da obra de Heidegger, Freud e Lacan. Cf. SANTOS, Renato dos; MOHR, Allan Martins. A (de)vida angústia de morte: considerações a partir da filosofia e da psicanálise. NATUREZA HUMANA (ONLINE), v. 20, p. 169-187, 2018.
}

SANTOS, Renato dos; DALBOSCO, Juliana Rodrigues. A afirmação da finitude como possibilidade para a responsabilização do desejo: notas a partir de Heidegger e Lacan. Griot : Revista de Filosofia, Amargosa - BA, v.19, n.1, p.215-225, fevereiro, 2019. 
de que ninguém morre, uma vez que o "a-gente" é ninguém. Encarar a morte não como própria morte implica na não afirmação da finitude e, por extensão, da própria existência e das possibilidades que a constitui. A tentativa de esquivar-se continuamente para o interior do mundo público acarreta num modo de enfrentar a existência que é, justamente, aquele que não consegue viver de acordo com o seu desejo, mas sempre dependente da demanda do desejo dos outros. Existe-se, portanto, preso na ditadura do impessoal. A respeito disso, assevera Heidegger (2012, p. 365):

\footnotetext{
Gozamos e nos satisfazemos como a-gente goza; lemos, vemos e julgamos sobre literatura e arte como a-gente vê e julga; mas nos afastamos também da 'grande massa' como a-gente se afasta; achamos 'escandaloso' o que agente acha escandaloso. A-gente, que não é ninguém determinado e que todos são, não como uma soma, porém, prescreve o modo-de-ser da cotidianidade.
}

O impessoal não se responsabiliza pela própria decisão, ou, antes, ele sequer consegue ter uma decisão própria, pois sua existência é guiada unicamente pelo que os outros ditam. Conforme veremos no segundo momento deste escrito, quando abordaremos a questão da responsabilização do desejo desde a psicanálise lacaniana, a existência tomada pelo impessoal não se configura como detentora de subjetividade, precisamente por não conseguir afirmar a própria decisão: o "a-gente é no modo do não-ser-si-mesmo e da impropriedade" (HEIDEGGER, 2012, p. 369). Ou seja, o si mesmo dá lugar ao "a-gente", que é "constituído no ser-publicamenteinterpretado que se expressa no falatório" (HEIDEGGER, 2012, p. 695).

Conforme adiantamos anteriormente, o Dasein somente consegue emancipar sua existência para autêntica, sair do impessoal, na medida em que afirma o que há de mais próprio de seu ser, isto é, a morte. Não se trata, porém, da morte tomada pela publicidade, como um fato, como algo "efetivamente real" (HEIDEGGER, 2012, p. 699), mas como a possibilidade mais própria que constitui seu modo de ser. Uma existência autêntica que afirma seu ser-para-a-morte deve, necessariamente, segundo Heidegger, "pôr em relevo os momentos que o constituem como entendimento da morte, no sentido de um ser que não foge e não encobre a possibilidade já caracterizada" (HEIDEGGER, 2012, p. 717).

O "lugar" que o filósofo concede ao ser-para-a-morte é aquele que pertence à própria estrutura do Dasein, como modo de ser, e que é encoberto pelo impessoal, quando o Dasein se afasta de si mesmo. Heidegger afirmará que o Dasein somente consegue sustentar seu ser-para-a-morte quando se afirma a angústia que aponta para ela: "na angústia diante da morte, o Dasein é conduzido diante de si mesmo e entregue a responsabilidade da possibilidade insuperável" (HEIDEGGER, 2012, p. 701).

Interessante notarmos que "responsabilidade" é o termo que o próprio Heidegger se utiliza para se referir a maneira pela qual o Dasein autêntico deve se posicionar diante de sua finitude. O Dasein inautêntico não consegue ter responsabilidade precisamente por transformar a angústia da morte em uma espécie de medo diante de um acontecimento que poderá vir ao seu encontro. Para o impessoal, a angústia representa fraqueza, algo que deve ser afastado. É comum

SANTOS, Renato dos; DALBOSCO, Juliana Rodrigues. A afirmação da finitude como possibilidade para a responsabilização do desejo: notas a partir de Heidegger e Lacan. Griot : Revista de Filosofia, Amargosa - BA, v.19, n.1, p.215-225, fevereiro, 2019. 
constatarmos em nossa sociedade comentários que pintam a angústia como sendo de natureza maligna, advinda das "forças do mal", típico de uma ditadura do impessoal que prega a felicidade como imperativo existencial, afastando o que há de mais próprio em nossa natureza ontológica, isto é, a angústia diante da finitude. Para Heidegger (2012, 701), isso não ocorre com um Dasein que é "seguro-de-si-mesmo", uma vez que o sujeito sabe o que quer e se responsabiliza pela sua finitude.

Ao chegarmos aqui, convém pensarmos de que forma a noção de angústia se relaciona à autenticidade e à finitude. Falamos anteriormente que o Dasein autêntico possui por característica, entre outras coisas, a afirmação da angústia. Mas o que, afinal, queremos dizer quando falamos em angústia, neste contexto? Na preleção de 1929, intitulada Que é metafísica?, Heidegger se ocupa em dissertar acerca do sentido dos conceitos de existência, nada e angústia. Para o filósofo, a angústia nos coloca em suspenso, retira o encobrimento ôntico do ser do Dasein, e coloca-o diante do nada.

\begin{abstract}
A angústia é sempre angústia de... é sempre angústia por..., mas não por isto ou aquilo. $O$ caráter de indeterminação daquilo diante de e por que nos angustiamos, contudo, não é apenas uma simples falta de determinação, mas a essencial impossibilidade de determinação (HEIDEGGER, 1979, p. 39).
\end{abstract}

A angústia não possui objeto, algo que possa ser localizado no interior do mundo. A "angústia manifesta o nada" (HEIDEGGER, 1979, p. 39). A indeterminação do objeto da angústia é, por excelência, o que a faz ser angústia, caso contrário seria um mero temor ou medo. Para essa indeterminação do objeto da angústia, Heidegger denomina de nada, ou finitude, justamente porque o nada revela aquilo que de mais próprio há em nossa estrutura ontológica, isto é, a finitude, ou uma abertura que nos coloca diante de nosso próprio ser do "aí". Daí o porquê o nada é o véu do ser, pois, assim como o nada, o ser não possui um objeto, algum ente que ele pudesse ser reduzido. Conforme esclarece Heidegger (1979, p. 40):

\footnotetext{
O nada se revela na angústia - mas não enquanto ente. Tampouco nos é dado como objeto. A angústia não é uma apreensão do nada. Entretanto, o nada se torna manifesto por ela e nela, ainda que não da maneira como se o nada se mostrasse separado, 'ao lado' do ente, em sua totalidade, o qual caiu na estranheza.
}

Importa enfatizarmos o fato de que a angústia revela ao ente humano o nada, a finitude e, igualmente, o ser. Por isso falamos que a angústia revela aquilo de mais próprio de nós mesmos, o sentido do nosso ser. Podemos agora entender o porquê o impessoal afasta-se da morte, ou antes da angústia da morte, pois o que essa angústia possibilita é justamente colocar o sujeito diante desta indeterminabilidade ontológica, algo que a publicidade não deseja nenhum pouco cogitar. Afinal, para o impessoal, o que importa são as "certezas", a comodidade do falatório que o faz sentir protegido. O problema - e é isto que estamos tentando mostrar ao leitor no presente texto - é que esse encobrimento faz com que o sujeito não seja ele mesmo, que ele se perca no superficial. Na tentativa de escapar da morte, do estranhamento

SANTOS, Renato dos; DALBOSCO, Juliana Rodrigues. A afirmação da finitude como possibilidade para a responsabilização do desejo: notas a partir de Heidegger e Lacan. Griot : Revista de Filosofia, Amargosa - BA, v.19, n.1, p.215-225, fevereiro, 2019. 
causado pela angústia, ele recorre ao conforto da alienação, ou seja, na posição de objeto.

Segundo Heidegger (1979, p. 40), "a angústia nos corta a palavra", isto é, ela nos retira daquele estado cômodo em que nos encontramos no interior dos entes. A angústia, assim, é uma espécie de navalha do real, no sentido de que sua manifestação rompe com aquelas imagens imaginárias construídas e consumidas pelo impessoal. Como lembra Heidegger $(1979,40)$, “o fato de nós procurarmos muitas vezes, na estranheza da angústia, romper o vazio silêncio com palavras sem nexo é apenas o testemunho da presença do nada".

Evidentemente que a angústia não se faz presente a todo instante, pois, caso contrário, o sujeito não suportaria conduzir sua existência. A angústia se manifesta em algum momento ou outro, nos fazendo recordar ${ }^{4}$ do sentido ontológico de nossa existência, ou, ainda, que somos finitos. Aliás, é por termos consciência da finitude e sermos seres de linguagem que falamos, que criamos obras de arte e tantos outros artefatos humanos, por exemplo. A angústia diante da finitude nos faz tomar alguma posição em nossa existência, seja de fuga ou afirmação. $O$ sujeito que não consegue afirmar sua finitude, e opta por refugiar-se na ditadura do impessoal, acaba por não conseguir responsabilizar-se por seu desejo.

Conforme veremos a seguir, aquilo que a psicanálise lacaniana afirma sobre o sujeito se responsabilizar pelo seu desejo, somente é possível se, primeiramente, o sujeito conseguir afirmar sua finitude, em termos heideggerianos. Isso porque, em nossa leitura, afirmar o desejo implica em aceitar as perdas que decorrem das decisões que são realizadas quando se afirma uma escolha $\mathrm{X}$ ou $\mathrm{Y}$. Ou seja, o sujeito somente consegue lidar com as perdas de sua existência se, antes, conseguir lidar com a perda do seu próprio ser, por meio da afirmação da finitude.

\section{A responsabilização do desejo em Lacan}

Ao pensar acerca da própria finitude o sujeito é abarcado pelo sentimento de angústia. Lacan em seu seminário 10, A angústia (1901-1989/2005), nos mostra que este afeto está ligado ao Real, por assinalar a emergência do desejo do Outro. A angústia está do lado daquilo que escapa à representação, na vertente do fantasma, onde mais podemos nos aproximar do Real do ser. Forbes (1985), acerca do final de uma análise, afirma que a angústia pode surgir em sua forma mais direta, naquilo que Freud chamou o "rochedo da castração" e que Lacan denominou como o "passe", "travessia". Pois, o sujeito ao final da análise, torna-se capaz de assumir a responsabilidade de sua posição e pelo desejo de perdurar como analista de sua própria experiência.

De acordo com Lacan, em seu seminário 6, O Desejo e a sua Interpretação, uma análise é uma terapêutica, ou seja, um tratamento psíquico que abrange diversos níveis do psiquismo sobre os fenômenos marginais ou residuais, como sonhos, lapsos,

\footnotetext{
${ }^{4}$ Em outro texto ocupei-me de refletir sobre o sentido que as palavras "nunca mais!" do corvo, do conto sob o mesmo título de Edgar Allan Poe, podem ser entendidas com a própria angústia, ou seja, tais palavras expressam um sentido que causa, em quem as ouve, recordar de algo que lhes é íntimo, isto é, a finitude. "Nunca mais!", portanto, é o corvo lembrando-nos de que nossa existência finda, declina-se, acaba. $C f$. SANTOS, Renato dos. Angústia, morte e finitude em Heidegger e Sartre. In: MOHR, Allan Martins; IÓRIO, Luiz Fernando Duran. (Org.). Átropos: escritos sobre morte, vida e pulsão. Curitiba: CRV, 2018.
}

SANTOS, Renato dos; DALBOSCO, Juliana Rodrigues. A afirmação da finitude como possibilidade para a responsabilização do desejo: notas a partir de Heidegger e Lacan. Griot : Revista de Filosofia, Amargosa - BA, v.19, n.1, p.215-225, fevereiro, 2019. 
chistes e sintomas. Essa terapêutica atua na modificação de estruturas chamadas neuroses ou neuropsicoses, inicialmente chamadas por Freud de neuropsicoses de defesa, interferindo nos diferentes níveis de realidade fenomênica na medida em que se coloca em jogo o desejo. A angústia determina os sintomas na medida em que é tomada no mecanismo do desejo, pois a defesa que se trata nas neuropsicoses "não é outra coisa senão o desejo" (LACAN, 1958-1959/2002, p. 13).

É a intervenção da angústia, se fizermos dela o ponto chave da determinação dos sintomas, mas na medida em que esta ou aquela atividade que vai entrar no jogo dos sintomas é erotizada, digamos melhor, quer dizer, tomada no mecanismo do desejo (LACAN, 19581959/2002, p. 13).

A psicanálise é a própria ética do desejo. O sujeito da psicanálise é o sujeito do desejo, delineado por Freud através da noção de inconsciente, marcado e movido pela falta. Faz-se necessário a reflexão acerca do desejo e do gozo: "desejo e gozo estão em campos diferentes, o desejo está no campo do simbólico e o gozo do lado do real" (KUSS, 2015, p. 72). O desejo é o efeito de uma perda originária de satisfação. Segundo Lacan:

Na definição da sublimação sem recalque há, implícito ou explícito, passagem do não-saber ao saber, reconhecimento disto, que o desejo nada mais é do que a metonímia do discurso da demanda. É a mudança como tal. Insisto - essa relação propriamente metonímica de um significante ao outro que chamamos de desejo, não é o novo objeto, nem o objeto anterior, é a própria mudança de objeto em si (LACAN, 1959/60/2008, p. 344).

Como já mencionamos em Heidegger, a angústia não tem um objeto, ela representa o nada. Assim como o desejo, que também não tem objeto de satisfação na realidade, portanto, se mantêm insatisfeito. Para Lacan, a angústia surge quando por meio de algum mecanismo aparece alguma coisa no lugar do objeto a, querendo tornar-se o objeto do desejo, como imagem da falta. Logo, se algo surge no lugar da falta, também nos causa angústia, têm-se aí a falta da falta. A perda de objeto em relação a angústia.

Portanto, afirmar a finitude, assim como a castração, evita com que queiramos tamponar a falta, para que então o desejo possa emergir. Como o desejo é (e)feito de uma falta e a falta é transmitida pelo Outro, o desejo é a própria falta no Outro. Através da entrada na linguagem e da castração ocorre a inscrição da falta e interdita-se o gozo sem limites dos primeiros tempos de vida, dando lugar para o desejo emergir. $O$ desejo é despertado justamente dessa interdição.

Mas é a fantasia que faz com que o desejo possa continuar existindo. Segundo Lacan, "a fantasia é a sustentação do desejo, não é o objeto que é a sustentação do desejo" (LACAN, 1964/2008, p. 181). Assim, o objeto do desejo ou é uma fantasia, ou é um engano. Pois, é através da fantasia que conseguimos lidar com o Real, é ela que indica ilusoriamente o que falta. Segundo Kuss (2015, p. 66), "a fantasia encena a presença da perda do gozo que foi perdido para adentrarmos na linguagem, gozo esse que, enquanto sujeito falantes, tornou-se inacessível". O desejo desliza de objeto em objeto, ele não se satisfaz plenamente, mas encontra satisfações parciais através da

SANTOS, Renato dos; DALBOSCO, Juliana Rodrigues. A afirmação da finitude como possibilidade para a responsabilização do desejo: notas a partir de Heidegger e Lacan. Griot : Revista de Filosofia, Amargosa - BA, v.19, n.1, p.215-225, fevereiro, 2019. 
fantasia e do objeto a. $\mathrm{O}$ desejo necessita de um outro para se constituir como tal. Ainda acerca da definição de desejo de Lacan, Miller explique que:

Um desejo evanescente, cujo único objeto e única satisfação é ser reconhecido pelo outro. Sem nenhuma substância, o que o dominaria, o enquadraria, o habitaria, seria o desejo de reconhecimento. De extrema sofisticação, nesse conceito, algo está num círculo lógico. Que é o desejo? É o desejo de fazer reconhecer o seu desejo (MILLER, 1997, p. 40).

De acordo com Lacan, "o desejo do homem é o desejo do Outro" (19011989/2005, p. 31). O desejo, a pulsão e o saber acerca da finitude são o que constituem e determinam a essência do nosso ser, nos diferenciando dos animais, pois, os animais não habitam o campo da linguagem. Os animais apenas são, e isso basta. $\mathrm{O}$ desejo e a angústia diante da finitude, inauguram-se quando adentramos o campo do simbólico, marcando assim, justamente a diferença do homem em relação a outros entes. Nessa perspectiva, é interessante retomarmos a passagem em que Heidegger afirma a especificidade do ente humano em relação aos demais entes no que se refere ao seu modo de existência. Para o filósofo:

Somente o homem existe. $O$ rochedo é, mas não existe. A árvore é, mas não existe. $O$ anjo é, mas não existe. Deus é, mas não existe. A frase: 'Somente o homem existe' de nenhum modo significa apenas que o homem é um ente real, e que todos os entes restantes são irreais e apenas uma aparência ou a representação do homem. A frase: 'O homem existe' significa: o homem é aquele ente cujo ser é assinalado pela in-sistência exsistente no desvelamento do ser a partir do ser e no ser (HEIDEGGER, 1979, p. 59).

O ser humano, o fala-ser - como dizia Lacan para designar que é ser porque fala - resulta do desejo do Outro, nasce do desejo do Outro veiculado na sua palavra, o que torna impossível, portanto, ser sem o Outro. É preciso o Outro como lugar para a existência, e de outros para lugar de identificação, espelho e referência de si mesmo.

Nos constituímos enquanto sujeitos de desejo através do Outro. Nascemos em um estado de total desamparo, incapazes de satisfazer nossas necessidades vitais, bem como de sobreviver sozinhos. Necessitamos do Outro materno que nos ajude, Outro que vai além de atender nossas necessidades básicas, ele demarca nossas bordas pulsionais, nos erogeniza, nos insere no campo simbólico e inscreve a falta, o que nos possibilita a constituição enquanto sujeitos de desejo. Dessa forma, desejamos o que os outros desejam, porque o desejo é o desejo do Outro, sendo desejo de desejo e desejo de ser desejado.

Para Lustoza (2006), a afirmação de Lacan de que o desejo do homem é o desejo do Outro, deve ser entendida no âmbito dos três registros: imaginário, simbólico e real. Para a psicanálise, na dimensão do imaginário, o que nos interessa é o objeto enquanto sendo alvo do querer do outro. Ou seja, "Eu quero o que o outro quer" querendo dizer "eu quero porque é o outro quem quer". O que me faz falta é aquilo que falta ao outro. Interessante lembrarmos que isto é justamente o que Heidegger descreveu acerca existência inautêntica, ou seja, estar preso à demanda do

SANTOS, Renato dos; DALBOSCO, Juliana Rodrigues. A afirmação da finitude como possibilidade para a responsabilização do desejo: notas a partir de Heidegger e Lacan. Griot : Revista de Filosofia, Amargosa - BA, v.19, n.1, p.215-225, fevereiro, 2019. 
desejo dos outros. Na dimensão simbólica, a afirmação de que o desejo é o desejo do Outro, pode ser entendida a partir do reconhecimento de que o Outro não se oferece como aquele que completa, tampona a falta. E sim, aquele que suscita a falta no Outro, que faz com que a própria falta do sujeito se reproduza. O Outro simbólico produz sentido para que o sujeito possa compreender a realidade. Na dimensão do real, a angústia viria precisamente como um afeto que sinaliza a emergência do desejo do Outro e ocorre quando desaparecem as coordenadas simbólicas que possibilitavam ao sujeito situar-se.

Em uma análise, convoca-se o sujeito à responsabilização por sua posição. $\mathrm{O}$ analista promove a implicação do sujeito em seu sofrimento, transformando-o em posição subjetiva. $O$ tratamento se dá através de uma experiência de investigação que possibilita saber do desejo inconsciente, através do método da associação livre. Nele, o analista pede que o analisando fale tudo que lhe vem à mente, sem qualquer censura. Assim, torna-se possível obter-se efeitos da linguagem pela via da fala na transferência, uma vez que o inconsciente é estruturado como linguagem.

Se podemos falar em uma ética da psicanálise, esta consiste justamente no tratamento daquilo que se chama, conforme Lacan (1901-1981/2008, p. 366), “experiência trágica da vida". Isto porque, o que está em questão numa análise, é a natureza do desejo inconsciente do sujeito, e não o ajustamento do sujeito dentro de um arcabouço de preceitos morais. A diferença da ética da psicanálise para a ética tradicional, por exemplo, está no ponto de que sua preocupação é voltada para o si mesmo do sujeito, e não com o social. Evidentemente, isso não significa que não haja implicações nas relações sociais ( $\hat{E}$ thos Universal), uma vez que, em nossa leitura, um sujeito somente consegue exercitar uma ética universal se, antes, ele conseguir responsabilizar-se pelo seu desejo. Do ponto de vista da ética da psicanálise, um sujeito só pode ser considerado culpado, na medida em que ele cede de seu desejo, ou como vimos, numa existência inautêntica, pode-se dizer que se trata de não assumir seu próprio ser.

É verdade, como sabemos, que o desejo pode comportar algo de conflituoso, causando até mesmo angústia. Daí o porquê muitas pessoas recusam-se em ir para a análise, pois acreditam que o causador de sua angústia são os outros, não se responsabilizando pela desordem da qual se queixam. Quando Lacan (19011981/2008, p. 367) questiona: "agiste conforme o desejo que te habita?", ele refere-se à responsabilização do sujeito diante do seu desejo.

Lacan, no Seminário 2, O eu na teoria de Freud e na técnica da psicanálise, nos diz que o desejo é inconsciente, sexual e se constitui a partir do Outro como falta articulada na linguagem e que "a análise deve visar à passagem de uma fala verdadeira, que junte o sujeito a um outro sujeito do outro lado do muro da linguagem" (LACAN, 1954-1955/1985, p. 310). Ou seja, há um Outro que dá resposta que não se espera, definindo assim o ponto terminal da análise. A análise é uma experiência que possibilita ao sujeito a afirmação da finitude e que o analisante reconheça no seu sofrimento, no seu sintoma, a sua própria autoria e participação, tornando-se responsável da sua condição de sujeito diante do seu desejo.

$O$ sujeito pode se colocar na posição objetal precisamente por não querer se deparar com a angústia de sua finitude. Muitas vezes procurando alento em alguma religião como forma de subterfúgio de sua angústia diante do Real. Não queremos,

SANTOS, Renato dos; DALBOSCO, Juliana Rodrigues. A afirmação da finitude como possibilidade para a responsabilização do desejo: notas a partir de Heidegger e Lacan. Griot : Revista de Filosofia, Amargosa - BA, v.19, n.1, p.215-225, fevereiro, 2019. 
com isso, dizer que a religião possui unicamente a finalidade de servir como fuga para seus fiéis. E sim, que ela é encarada por muitos como forma de preenchimento unívoco da falta.

Numa existência autêntica, ou também num final de análise, onde o sujeito sabe lidar com suas perdas, diante dessa angústia, ele assume um papel de protagonista de sua existência e consegue se responsabilizar pelo seu desejo. A análise, nesse sentido, serve como uma ferramenta que possibilita o sujeito lidar com este sofrimento decorrente da falta, deste nada que falou Heidegger. Evidentemente que a análise não objetiva eliminar esta falta ontológica, mas tão somente descontruir os fantasmas que o sujeito construiu para afastar o que lhe é mais próprio, constitutivo de sua estrutura ontológica, qual seja, sua finitude.

\section{Conclusão}

A tese que procuramos sustentar, ao longo deste capítulo, foi a de que o ser humano somente consegue ter alguma possibilidade de responsabilização do desejo se, primeiramente, ele afirmar a finitude de sua própria existência. Conforme vimos em Heidegger, o ente humano - que o filósofo denomina de Dasein - é o único dentre os demais entes que se angustia, isto é, que se defronta pelo findar da sua existência. Se, em Heidegger, o Dasein lançado em uma existência inautêntica busca encobrir a angústia diante do nada, para Lacan, quando o sujeito não consegue se responsabilizar pelo seu desejo, recai numa posição objetal. Ou seja, por não ter de enfrentar a angústia da finitude (da falta, das perdas), ele opta por não sair desta posição e ser um sujeito desejante.

Paradoxalmente, é somente porque há falta, finitude, nada, que há desejo e angústia. $\mathrm{O}$ desejo é o que nos move. Ele é o horizonte de possibilidade que faz com que o sujeito transcenda uma posição de mero objeto do Outro. Querer negar a angústia da finitude, é negar o próprio estatuto de sujeito de desejo, ou como diria Heidegger, o "si mesmo". Interessante lembrar que, mesmo o sujeito que se recusa afirmar a finitude, na ilusão de que não irá se angustiar, acaba por enganar-se, pois, conforme Goethe, retomado por Freud (1930-1936/2010, p. 31) n'O mal-estar na civilização: "Nada é mais difícil de suportar que uma sucessão de dias belos". Não havendo falta, não há desejo e, por conseguinte, uma existência autêntica.

Ora, tanto para Heidegger, por meio da afirmação da angústia frente à morte, quanto para Lacan, onde o sujeito assumiu a tragédia de sua existência - no final de análise -, é a afirmação da finitude que possibilita a responsabilização do desejo, de ser autêntico ou, se preferir, sujeito. Portanto, para retomarmos a canção de Nelson Sargento, mesmo a vida sendo uma "luta tremenda para sobreviver", frente à angústia da iminente finitude da existência e das perdas da vida, sendo um sujeito de desejo, "mesmo assim lhe asseguro que quero viver".

\section{Referências}

SANTOS, Renato dos; DALBOSCO, Juliana Rodrigues. A afirmação da finitude como possibilidade para a responsabilização do desejo: notas a partir de Heidegger e Lacan. Griot : Revista de Filosofia, Amargosa - BA, v.19, n.1, p.215-225, fevereiro, 2019. 
FORBES, Jorge. A angústia. Palestra apresentada ao "Simpósio sobre Ansiedade e Benzodiazepínicos", promovido pelo Departamento de Neuropsiquiatria da Faculdade de Medicina da universidade de São Paulo, em 12 de abril de 1985. Disponível em: $<$ http://www.jorgeforbes.com.br/br/artigos/a-angustia.html $>$. Acesso em: 05 de setembro de 2018.

FREUD, Sigmund (1930-1936). O mal-estar na civilização, novas conferências introdutórias à psicanálise e outros textos. Trad. Paulo César de Souza. São Paulo: Companhia das letras, 2010.

HEIDEGGER, Martin. Que é metafísica? In: Conferências e escritos filosóficos. São Paulo: Abril Cultural, 1979.

HEIDEGGER, Martin . Ser e tempo. Campinas: Unicamp; Petrópolis: Vozes, 2012.

KUSS, Ana S. S. Amor, desejo e psicanálise. Curitiba: Juruá, 2015.

LACAN, Jacques (1954-1955) O Seminário, livro 2: o eu na teoria de Freud e na técnica da psicanálise/Jacques Lacan; texto estabelecido por Jacques-Alain Miller; versão brasileira Marie Christine Lasnik Penot; com a colaboração de Antônio Luiz Quinet de Andrade, - Rio de Janeiro: Zahar, 1985.

LACAN, Jacques (1958-1959) O Seminário, livro 6: o desejo e sua interpretação/Jacques Lacan; texto estabelecido por Jacques-Alain Miller, versão brasileira Cláudia Berliner. Rio de Janeiro: Zahar, 2002.

LACAN, Jacques (1901-1981) O Seminário, livro 7: a ética da psicanálise/Jacques Lacan; texto estabelecido por Jacques-Alain Miller; versão brasileira Antonio Quinet. Rio de Janeiro: Zahar, 2008.

LACAN, Jacques (1901 -1989) O Seminário, livro 10: a angústia/Jacques Lacan; texto estabelecido por Jacques-Alain Miller; versão final Angelina Harari e preparação de texto André Telles; tradução Vera Ribeiro. Rio de Janeiro: Zahar, 2005.

LACAN, Jacques (1901 -1981) O Seminário, livro 11: os quatro conceitos fundamentais da psicanálise (1964) /Jacques Lacan; texto estabelecido por Jacques-Alain Miller; tradução M.D. Magno. Rio de Janeiro: Zahar, 2008.

LUSTOZA, Rosane Zétola. A angústia como sinal do desejo do Outro. Revista MalEstar e Subjetividade, Fortaleza Vol.6 n. 1, p. 44-66, Março, 2006.

MILLER, Jacques-Alain. Lacan elucidado: palestras no Brasil. Rio de Janeiro: Zahar, 1997.

SANTOS, Renato dos; MOHR, Allan Martins. A (de)vida angústia de morte: considerações a partir da filosofia e da psicanálise. Natureza Humana (online), v. 20, p. 169-187, 2018.

SANTOS, Renato dos. Angústia, morte e finitude em Heidegger e Sartre. In: MOHR, Allan Martins; IÓRIO, Luiz Fernando Duran. (Org.). Átropos: escritos sobre morte, vida e pulsão. Curitiba: CRV, 2018. p. 71-87.

\section{Contribuição dos autores}

Renato dos Santos contribuiu com a pesquisa sobre Heidegger. Juliana Rodrigues Dalbosco contribuiu com a pesquisa sobre Lacan. De forma conjunta, os autores desenvolveram a introdução, a tese central, a conclusão e aprovaram a versão final do artigo.

Autor(a) para correspondência: Renato dos Santos, Pontifícia Universidade Católica do Paraná, Rua Imaculada Conceição, 1155 - Prado Velho, 80215-901, Curitiba - PR, Brasil. renatodossantos1@hotmail.com

SANTOS, Renato dos; DALBOSCO, Juliana Rodrigues. A afirmação da finitude como possibilidade para a responsabilização do desejo: notas a partir de Heidegger e Lacan. Griot : Revista de Filosofia, Amargosa - BA, v.19, n.1, p.215-225, fevereiro, 2019. 